\title{
Subunits shared by eukaryotic nuclear RNA polymerases
}

\author{
Nancy A. Woychik, Sha-Mei Liao, Peter A. Kolodziej, and Richard A. Young \\ Whitehead Institute for Biomedical Research, Cambridge, Massachusetts 02142 USA; Department of Biology, Massachusetts \\ Institute of Technology, Cambridge, Massachusetts 02139 USA
}

RNA polymerases I, II, and III share three subunits that are immunologically and biochemically indistinguishable. The Saccharomyces cerevisiae genes that encode these subunits $(R P B 5, R P B 6$, and $R P B 8)$ were isolated and sequenced, and their transcriptional start sites were deduced. $R P B 5$ encodes a 25-kD protein, $R P B 6$, an 18-kD protein, and $R P B 8$, a 16-kD protein. These genes are single copy, reside on different chromosomes, and are essential for viability. The fact that the genes are single copy, corroborates previous evidence suggesting that each of the common subunits is identical in RNA polymerases I, II, and III. Furthermore, immunoprecipitation of RPB6 coprecipitates proteins whose sizes are consistent with RNA polymerase I, II, and III subunits. Sequence similarity between the yeast RPB5 protein and a previously characterized human RNA polymerase subunit demonstrates that the common subunits of the nuclear RNA polymerases are well conserved among eukaryotes. The presence of these conserved and essential subunits in all three nuclear RNA polymerases and the absence of recognizable sequence motifs for DNA and nucleoside triphosphate-binding indicate that the common subunits do not have a catalytic role but are important for a function shared by the RNA polymerases such as transcriptional efficiency, nuclear localization, enzyme stability, or coordinate regulation of rRNA, mRNA, and tRNA synthesis.

[Key Words: RNA polymerase; subunit; transcription; Saccharomyces cerevisiae]

Received September 18, 1989; revised version accepted January 3, 1990.

Eukaryotic RNA polymerases I, II, and III are highly conserved enzymes that are responsible for rRNA, premRNA, and small stable RNA synthesis, respectively (Lewis and Burgess 1982; Sentenac 1985). Although these nuclear RNA polymerases differ in promoter utilization, their shared functions are as noteworthy as their differences. The RNA polymerases are multisubunit enzymes that must properly initiate, elongate, and terminate the synthesis of RNA in a template-dependent fashion.

The common functions of the three RNA polymerases are reflected in features that are shared by these enzymes. The two large subunits of RNA polymerase I are related in size and sequence to the two large subunits of RNA polymerases II and III (Allison et al. 1985; Memet et al. 1988a). Considerable effort has gone into studying these two RNA polymerase subunits because they are thought to have important roles in transcription initiation and because the genes that encode them were among the first subunit genes to be isolated from the yeast Saccharomyces cerevisiae (Young and Davis 1983; Ingles et al. 1984; Allison et al. 1985; Riva et al. 1986; Sweetser et al. 1987; Memet et al. 1988b), Drosophila (Searles et al. 1982; Greenleaf 1983; Biggs et al. 1985; Faust et al. 1986; Falkenburg et al. 1987), and mammals (Cho et al. 1985; Corden et al. 1985; Ahearn et al. 1987). The other major feature shared by the nuclear RNA polymerases is a set of three subunits that appear to be common to the three enzymes in all eukaryotes examined thus far (Sentenac 1985). The structure and function of these three subunits are poorly defined, in part, due to the fact that the genes that encode them have not yet been described.

The $S$. cerevisiae nuclear RNA polymerases are among the best studied eukaryotic RNA polymerases. These enzymes are each composed of 10-13 polypeptides (Sentenac 1985). The three subunits that appear to be shared by the nuclear RNA polymerases, with apparent molecular masses of 27,23 , and $14.5 \mathrm{kD}$, are referred to here as RPB5, RPB6, and RPB8, respectively. Whether isolated from RNA polymerase I, II, or III, any one of the common subunits appears to be identical in all three enzymes by SDS-polyacrylamide gel mobility, fingerprint patterns (Buhler et al. 1976b; Valenzuela et al. 1976), isoelectric point (Buhler et al. 1976b), and antigenic recognition (Buhler et al. 1980; Huet et al. 1982; Breant et al. 1983). However, it is not yet clear whether each of the common subunits is actually identical or just very closely related.

To better understand the structure and function of eukaryotic RNA polymerases, the genes that encode $S$. cerevisiae RNA polymerase subunits are being isolated and used to examine the roles of subunits in transcription (Young and Davis 1983; Ingles et al. 1984; Allison et al. 


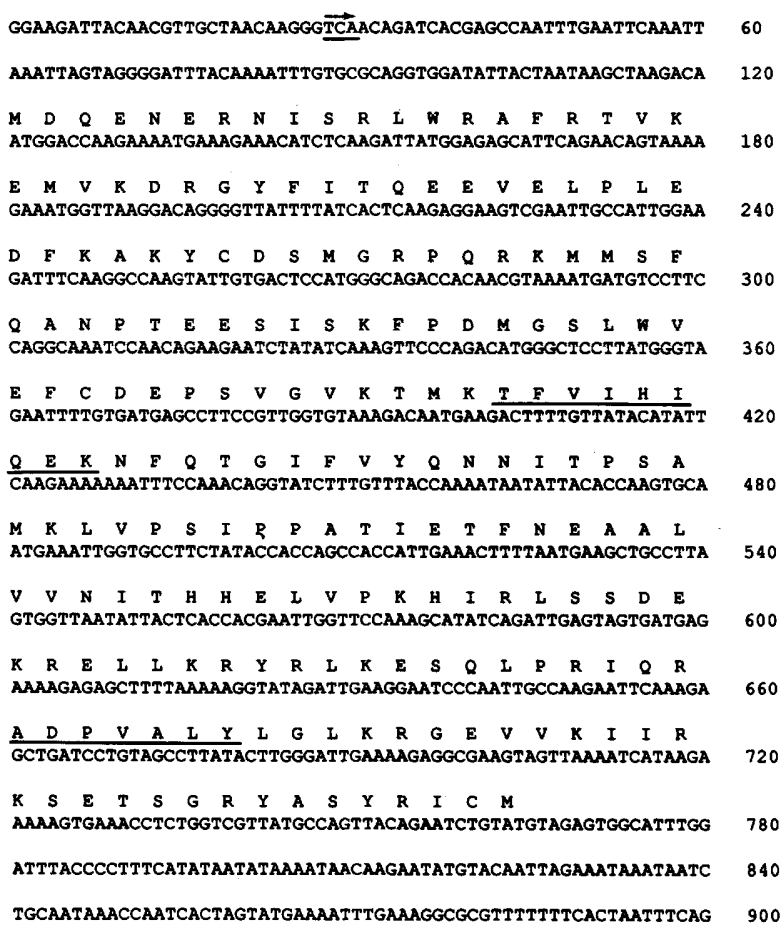

Figure 1. Sequence of RPBS DNA and the predicted amino acid sequence of the RPB5 subunit. The tryptic RPB5 peptides TFVIHIQEK and ADPVALY are underlined. The mRNA start site $( \pm 1)$ is underlined and marked with an arrow.

1985; Riva et al. 1986; Mann et al. 1987; Sweetser et al. 1987; Memet et al. 1988b; Kolodziej and Young 1989; Woychik and Young 1989). Here, we describe the isolation and characterization of genes that encode the three common subunits of yeast RNA polymerases I, II, and III.

\section{Results}

General strategy for isolation of the common subunit genes

Yeast RNA polymerase II was purified using a standard procedure (Valenzuela et al. 1978). The 27-, 23-, and $14.5-\mathrm{kD}$ proteins (RPB5, RPB6, and RPB8) were isolated from SDS-polyacrylamide gels. Tryptic fragments of each of the three subunits were generated and separated by high-performance liquid chromatography (HPLC), and at least two peptide sequences were obtained from each subunit. The peptide sequences obtained for RPB5, RPB6, and RPB8 were used to design DNA oligonucleo- tides for use in isolating the RNA polymerase subunit genes (Table 1).

The oligonucleotides were labeled and used to probe Southern blots of $S$. cerevisiae genomic DNA cleaved with various restriction enzymes. The hybridization and wash conditions that produced the best signal-to-noise ratio were determined for each oligonucleotide.

\section{RPB5}

$R P B 5$ was cloned from a $\lambda E M B L 3 a$ library of $S$. cerevisiae S288C genomic DNA. From six plates containing $\sim 2 \times 10^{4}$ plaques, we selected a total of $10 \lambda \mathrm{EMBL} 3 \mathrm{a}$ recombinant clones that produced positive signals with radiolabeled RPB5 oligonucleotides. Each plate contained $\sim 50$ plaques that produced a strong positive signal. All 10 clones selected contained an 8-kb Sall DNA restriction fragment that hybridized to both RPB5 probes in a Southern blot. The 8-kb Sall DNA fragment was subcloned into plasmid pBluescript $\mathrm{KS}^{+}$to produce pRP51, and this clone was subjected to sequence analysis using as primers the same oligonucleotides that were used as probes to isolate the $\lambda E M B L 3 a$ clones. The sequence confirmed that pRP51 contains RPB5 DNA because the DNA sequence accurately predicts the RPB5 amino acid sequence determined by peptide sequencing. The RPB5 sequence was then obtained for both DNA strands and is shown in Figure 1.

The RPB5 transcription initiation start site was deduced by primer extension of $S$. cerevisiae poly $(\mathrm{A})^{+}$ RNA (Fig. 1). This information and the partial amino acid sequences obtained for RPB5 protein permitted unambiguous assignment of the RNA polymerase subunitcoding sequence. The RPB5 sequence predicts a protein of 215 amino acid residues with a molecular mass of 25,038 daltons. This is only slightly less than the apparent molecular mass of $27 \mathrm{kD}$ estimated by SDSPAGE.

A human 23-kD RNA polymerase II subunit gene has recently been isolated and sequenced (Pati and Weissman 1989) and is a homolog of the yeast RPB5 gene. The two proteins are similar in length. Yeast RPB5 consists of 215 amino acid residues, and its human relative contains 197 residues. Alignment of the amino acid sequences of the human and yeast RNA polymerase subunits revealed that $30 \%$ of the amino acids are identical (Fig. 2). An additional $26 \%$ of the residues are conservative amino acid replacements, scoring +1 or greater in the mutation data matrix of Dayoff et al. (1983).

Table 1. DNA oligonucleotides

\begin{tabular}{ll}
\hline Gene & Gene-specific oligonucleotides $\left(5^{\prime} \rightarrow 3^{\prime}\right)$ \\
\hline$R P B 5$ & 1. TT(T/C)-GTI-ATI-CA(T/C)-ATI-CA(A/G)-GA(A/G)-AA \\
2. GCI-GA(T/C)-CCI-GTI-GCI-ITI-TA \\
RPB6 & 1. ATI-GTI-ACI-GGI-GGI-AA/T/C)-GGI-CCI-GA(A/G)-GA(T/C)-TT(T/C)-CA(A/G)-CA \\
& 2. ATG-AA(T/C)-GCI-CCI-GTI-TT(T/C)-GTI-GA(T/C)-ITI-GA(A/G)-CA(A/G)-GA \\
$R P B 8$ & 1. TGG-IGI-CCI-CCI-CA(A/G)-GCI-GGI-GA \\
\hline
\end{tabular}




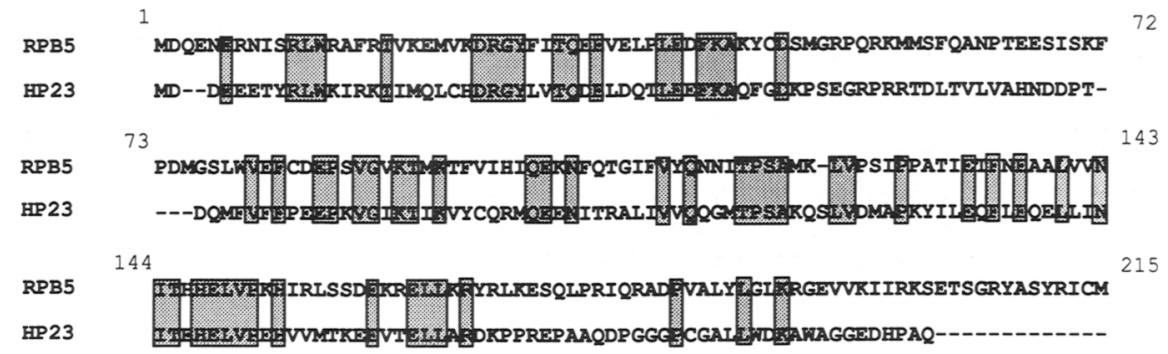

Figure 2. Sequence similarities between RPB5 and the $23-\mathrm{kD}$ human RNA polymerase II HP23 subunit. Identical amino acid residues are boxed and shaded.

\section{RPB6}

The RPB6 DNA probes were found to produce signals with $\lambda E$ EMBL3a vector DNA; to avoid this problem, $R P B 6$ was cloned from a yeast plasmid sublibrary. A plasmid library enriched in RPB6 DNA was constructed. To deduce which genomic DNA restriction fragments were large enough to be likely to contain the entire $R P B 6$ gene, Southern blots containing $S$. cerevisiae genomic DNA digested with a variety of restriction enzymes were probed with the RBP6-specific oligonucleotides. Both RBP6 oligonucleotides hybridized to a $1.5-\mathrm{kb}$ HindIII fragment. S. cerevisiae genomic DNA was digested with HindIII, and DNA fragments in the range of 1-2 kb were gel-purified and ligated to HindIII-cut pBluescript II $\mathrm{KS}^{+}$DNA. Escherichia coli cells were transformed with this DNA, the plasmid library was screened with the RPB6 oligonucleotide probes, and signal-producing colonies were isolated. One positive clone was obtained from $\sim 800$ colonies. Plasmid prepared from this clone contained a $1.5-\mathrm{kb}$ HindIII DNA fragment.

The sequence of the entire $1.5-\mathrm{kb}$ HindIII DNA fragment was obtained by sequencing both strands, and a single open reading frame predicted a protein containing the two amino acid sequences obtained from RPB6 tryptic peptides (Fig. 3). However, this open reading frame did not encode any methionine residues upstream of the coding sequence for the first of the two peptide sequences. This observation led to the suspicion that $R P B 6$ mRNA might be spliced.

Two observations confirm that RBP6 contains an intervening sequence. First, the yeast splice signal sequence 5'-TACTAAC-3' occurs upstream of the open reading frame obtained from the genomic DNA clone. This sequence is preceded by a potential $5^{\prime}$ splice junction donor sequence $\left(5^{\prime}\right.$-GTATGT-3') and is followed by a $3^{\prime}$ splice acceptor junction $\left(5^{\prime}\right.$-CAG-3') 16 nucleotides downstream, suggesting an intron of $76 \mathrm{bp}$ (Fig. 4A). Second, reverse transcriptase-catalyzed primer extension of both wild-type and rna2-1 poly(A) ${ }^{+}$mRNA demonstrated that unspliced $R P B 6$ precursor RNAs accumulate in an rna2-1 strain (Fig. 4B). S. cerevisiae rna2-1 mutants are temperature-sensitive for pre-mRNA splicing at $37^{\circ} \mathrm{C}$. Primer extension of RNA from wild-type yeast indicates that $R P B 6$ mRNA has three different $5^{\prime}$ ends (Fig. 4B). RNA was isolated from rna2-1 cells grown at the permissive temperature $\left(23^{\circ} \mathrm{C}\right)$ or shifted to the non- permissive temperature $\left(37^{\circ} \mathrm{C}\right)$ for $1 \mathrm{hr}$. Primer extension of $R P B 6$ poly $(\mathrm{A})^{+}$RNA from rna2-1 cells grown at the nonpermissive temperature revealed the presence of three RNAs $\sim 76$ nucleotides longer than each of the wild-type mRNAs (Fig. 4B, rna2-1 $37^{\circ} \mathrm{C}$ ). In contrast, primer extension of wild-type RNA or RNA prepared from rna2-1 cells grown at permissive temperature did not reveal the three RPB6 pre-mRNAs (Fig. 4B, wildtype and rna2-1 $23^{\circ} \mathrm{C}$. Additional primer extension experiments using two unique DNA oligonucleotides as primers confirmed the results shown in Figure 4B. The presence of these three pre-mRNAs in mutant rna2-1 cells verifies the presence of a 76-bp intron near the beginning of the RPB6 gene.

The sequence of the RPB 6 gene, the positions of the $R P B 6$ transcript start sites, and the predicted amino acid sequence of the RNA polymerase subunit are shown in Figure 3. The spliced mRNA is translated into a 155-residue protein with a molecular mass of 17,857 daltons. This is considerably less than the apparent molecular mass of $23 \mathrm{kD}$ estimated by SDS-PAGE. However, this subunit is phosphorylated (Buhler et al. 1976a; Bell et al. 1977), and phosphorylated proteins often migrate aberrantly on SDS-polyacrylamide gels. The RPB6 protein does not appear similar to any protein sequence accessible through conventional data bases.

\section{RPB8}

A plasmid library enriched for $R P B 8$ DNA was constructed to facilitate the isolation of the gene. Southern analysis of restriction enzyme-digested S. cerevisiae genomic DNA showed that the RPB8-specific oligonucleotide probes (Table 1) hybridized to a 7-kb EcoRI fragment. Yeast genomic DNA was digested with EcoRI, 6to 8-kb DNA fragments were purified and ligated to pBluescript II $\mathrm{KS}^{+}$cleaved with EcoRI, and $\sim 800 \mathrm{E}$. coli transformants were screened with the $R P B 8$ probe. Restriction mapping of plasmid DNA from the three positive clones selected revealed that each contained a $7-\mathrm{kb}$ $E c o R I$ insert with identical internal restriction sites. The DNA sequence of one of these clones was determined, and the predicted RPB8 amino acid sequence was found to contain the three peptide sequences obtained from proteolytic fragments of RPB8 (Fig. 5). The RPB 8 mRNA start site was deduced from primer extension analysis of poly $(\mathrm{A})^{+}$RNA. The predicted RPB8 protein is 146 amino acids long and has a molecular mass of 16,468 daltons, 


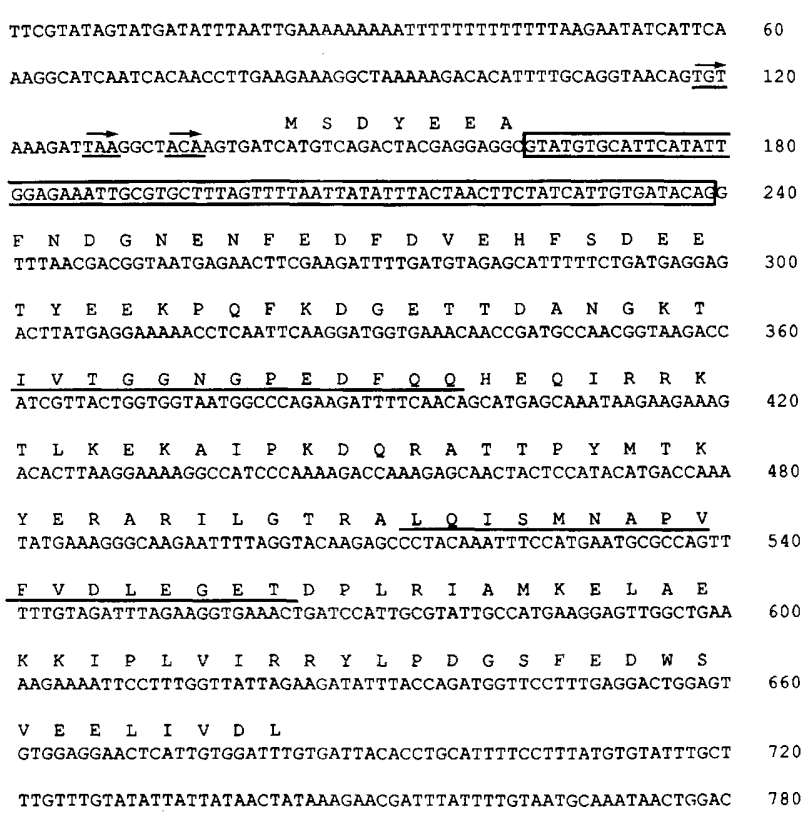

Figure 3. Sequence of $R P B 6$ DNA and the predicted amino acid sequence of the RPB6 subunit. The tryptic peptides IVTGGNGPEDFQQ and LQISMNAPVFVDLEGET are underlined. The approximate mRNA start sites $( \pm 1)$ are underlined and marked with an arrow. The 76-bp intron is boxed. similar to the molecular mass of $14.5 \mathrm{kD}$ estimated by SDS-PAGE. Computer search of conventional data bases did not reveal the existence of any protein sequences significantly similar to RPB8.

\section{Copy number and chromosomal location of common subunit genes}

Southern blots containing immobilized restriction digests of $S$. cerevisiae genomic DNA were probed with $R P B 5, R P B 6$, and $R P B 8$ DNA fragments at moderate stringency, as described in Methods (Fig. 6). The pattern of hybridization with each probe, in which only a single band producing a strong signal was observed, indicated that $R P B 5, R P B 6$, and $R P B 8$ are single-copy genes in haploid yeast. The pattern of hybridization obtained with $R P B 5, R P B 6$, and $R P B 8$ DNA fragment probes did not change over a range of hybridization and wash conditions and was the same as that obtained with the oligonucleotide probes used for gene isolation and characterization.

The RPB5 gene was localized to chromosome II, $R P B 6$ to chromosome XVI, and $R P B 8$ to chromosome XV by probing a Southern blot containing S. cerevisiae chromosome separated by pulsed-field electrophoresis with gene-specific DNA fragment (not shown).

A.
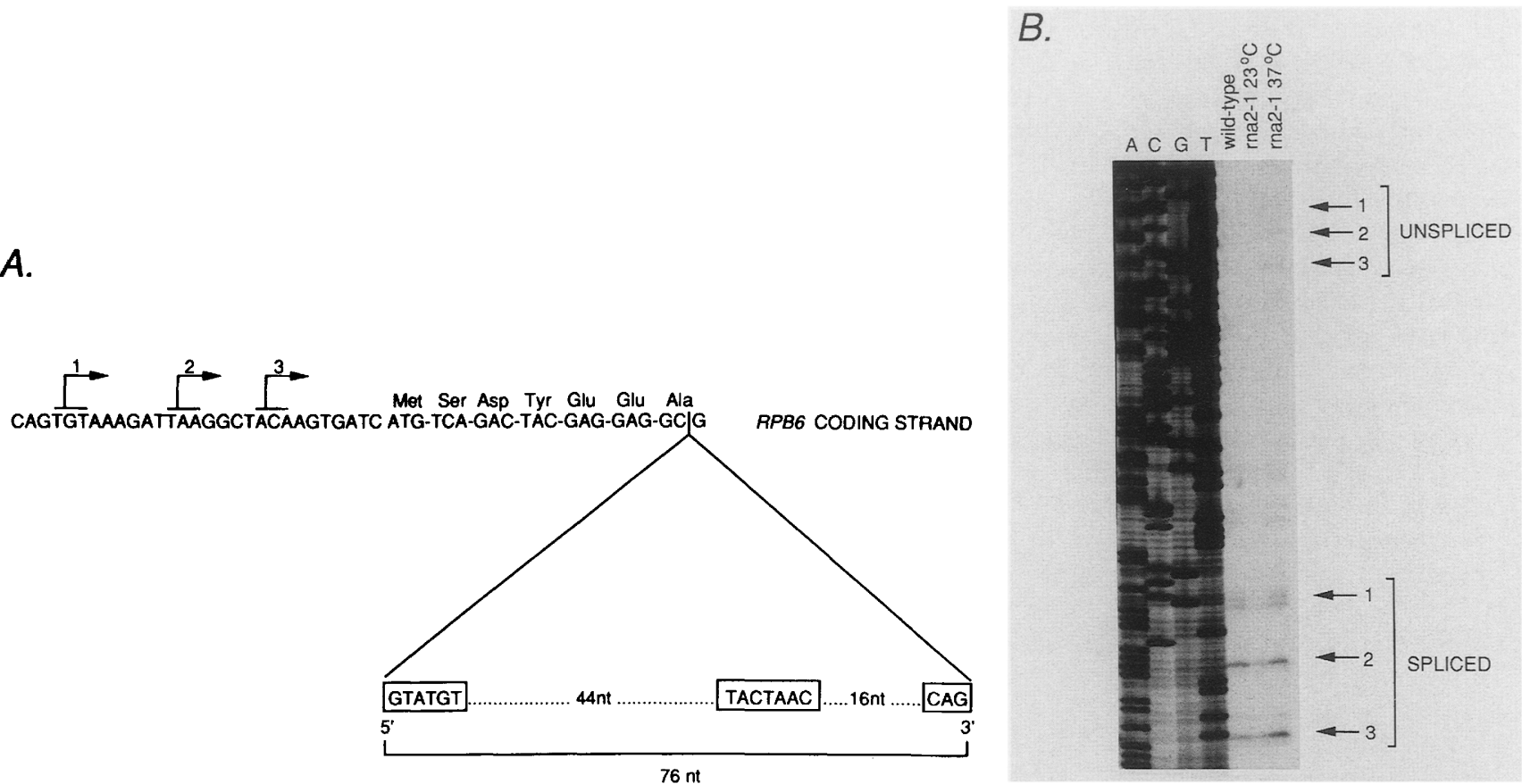

Figure 4. Identification of a 76-bp intron near the amino terminus of the RPB6 gene. $(A)$ Position and features of the 76-nucleotide $R P B 6$ intervening sequence. The 5 ' splice donor sequence, splice signal sequence, and $3^{\prime}$ splice junction are boxed. The start sites ( \pm 1$)$ of the three RPB6 transcripts are numbered. $(B)$ Primer extension analysis of wild-type and ma2-1 poly $(A)+R N A$. The end-labeled DNA oligonucleotide 5'-CTCCTCATCAGAAAAATGCTCTACATC-3' was annealed to wild-type poly(A) ${ }^{+}$RNA (wild-type) or rna2-1 poly $(\mathrm{A})^{+}$RNA prepared from cells grown at the permissive temperature (ma2-1, $23^{\circ} \mathrm{C}$ ), or shifted to the nonpermissive temperature $\left(37^{\circ} \mathrm{C}\right)$ for $1 \mathrm{hr}\left(\mathrm{rna} 2-1,37^{\circ} \mathrm{C}\right)$. After reverse transcriptase-catalyzed DNA synthesis, equivalent amounts of each reaction were loaded adjacent to sequencing reactions primed with the same oligonucleotide used for primer extension. The three transcript start sites correspond to those represented in $A$. Each lane represents the primer extension products obtained using 0.7 pmole of labeled oligonucleotide annealed to $5 \mu \mathrm{g}$ of poly(A) ${ }^{+}$RNA. The sequencing reactions were run adjacent to the primer extension products to accurately determine transcript lengths. 


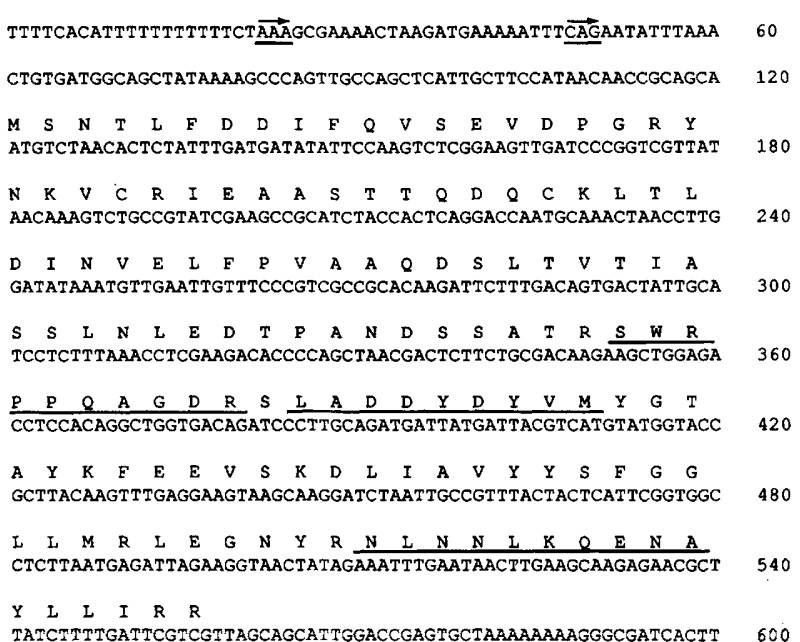

Figure 5. Sequence of $R P B 8$ DNA and the predicted amino acid sequence of the RPB8 subunit. The tryptic peptides SWRPPQAGDR, LADDYDYVM, and NLNNLKQENA are underlined. The approximate mRNA start sites $( \pm 1)$, determined by primer extension, are underlined and marked with an arrow.

Immunoprecipitation demonstration that the RPB6 gene product is a component of RNA polymerases I, II, and III

The fact that RPB5, RPB6, and RPB8 are single-copy genes and that closely related sequences were not detected by hybridization to whole genome Southern blots indicates that each of the common subunits is identical in the three nuclear RNA polymerases. To confirm that the product of one of these genes, $R P B 6$, is actually incorporated into all three nuclear RNA polymerases, we used immunoprecipitation of specific RNA polymerase subunits to investigate their association with the three nuclear RNA polymerases. An influenza hemagglutinin epitope-coding sequence (Field et al. 1988) was added to the amino-terminal coding sequence of $R P B 3$, which en- codes a subunit unique to RNA polymerase II (Kolodziej and Young 1989), and to the amino-terminal-coding sequence of $R P B 6$. The modified $R P B 3$ and $R P B 6$ gene products complement their respective deletion mutations, and cells containing either epitope-tagged protein grow at wild-type rates throughout the normal temperature range for wild-type cells.

Immunoprecipitation of epitope-tagged RPB3 from $\left[{ }^{35} \mathrm{~S}\right]$ methionine-labeled extracts results in the coprecipitation of the 10 subunits expected for RNA polymerase II (Fig. 7; Sentenac 1985). In contrast, immunoprecipitation of epitope-tagged RPB6 from [ $\left.{ }^{35} \mathrm{~S}\right]$ methionine-labeled extracts not only results in the precipitation of the 10 RNA polymerase II subunits but also in polypeptides whose sizes are consistent with those described for the larger subunits of yeast RNA polymerases I and III (Sentenac 1985). These large RNA polymerase polypeptides have mobilities consistent with RPA1 (190 kD), RPA2 (135 kD), RPA4 (43 kD), and RPAC5 (40 kD) and with $\mathrm{RPCl}(160 \mathrm{kD}), \mathrm{RPC} 2(128 \mathrm{kD})$, and RPC3 (82 kD). A shorter exposure allows the resolution of $\mathrm{RPCl}$ and RPB2. With the exception of the common subunits RPB5, RPB6, and RPB8, the smaller subunits described for RNA polymerases I and III are not clearly observed in this experiment. This is due to the appearance of lower levels of RNA polymerases I and III relative to RNA polymerase II and to the small number of methionine residues in the smaller proteins in Figure 7 . These results indicate that the RPB6 gene product is assembled

\section{All three RNA polymerase common subunits are essential for cell viability}

Most, but not all, of the RNA polymerase subunit genes studied thus far are essential for yeast cell viability (Nonet et al. 1987; Sweetser et al. 1987; Kolodziej and Young 1989; Woychik and Young 1989). To determine whether the common subunits are essential for cell viability, each of the common subunit genes was replaced with a yeast nutritional marker. One chromosomal copy
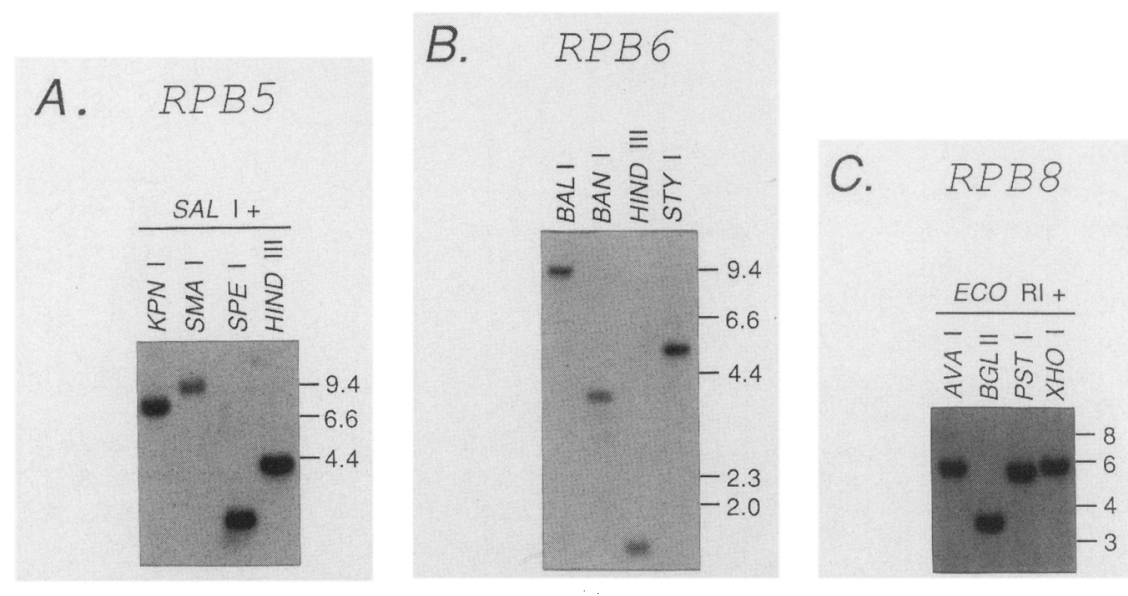

Figure 6. Copy number of the $R P B 5(A), R P B 6,(B)$, and $R P B 8(C)$ genes. Genomic DNA prepared from haploid yeast cells was digested with the enzyme(s) indicated. DNA restriction fragments used to radiolabel probes are described in Methods. DNA size markers (in $\mathrm{kb}$ ) are shown at right. 


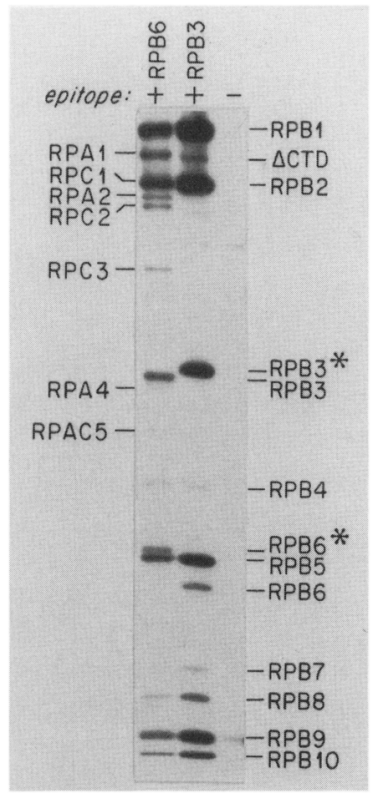

Figure 7. Immunoprecipitation of epitope-tagged RPB6 and RPB3. (Lane RPB6) Immunoprecipitation of RNA polymerases I, II, and III using epitope-tagged RPB6 (RPB6*). RPA1, RPA2, and RPA4 represent bands with mobilities of the large RNA polymerase I subunits; RPC1, RPC2, and RPC3 indicate bands with mobilities of RNA polymerase III subunits. RPAC5 is a subunit common to both RNA polymerase I and III. (Lane $R P B 3$ ) Immunoprecipitation of RNA polymerase II subunits with epitope-tagged RPB3 $\left[R P B 3^{*}\right.$ ). Band $\triangle \mathrm{CTD}$ is a proteolytic product of the RPBl subunit that lacks the 26-heptapeptide repeat units at the carboxyl terminus of the protein. The mobility shifts seen for the RPB3* and RPB6* subunits are due to the addition of the 9-amino-acid influenza hemagglutinin epitope. The apparent molecular masses of the RNA polymerase II subunits are $220 \mathrm{kD}$ (RPB1), $150 \mathrm{kD}$ (RPB2), $44.5 \mathrm{kD}$ (RPB3), $32 \mathrm{kD}$ (RPB4), $27 \mathrm{kD}$ (RPB5), $23 \mathrm{kD}$ (RPB6), $16 \mathrm{kD}$ (RPB7), $14.5 \mathrm{kD}$ (RPB8), $12.6 \mathrm{kD}$ (RPB9), and $10 \mathrm{kD}$ (RPB10).

of each gene in diploid yeast cells was replaced using the method of Rothstein (1983). This method relies on homologous recombination of $R P B 5-$, $R P B 6-$, or $R P B 8-$ flanking DNA with the chromosomal DNA, resulting in the replacement of the chromosomal copy of the subunit gene with a selectable marker. Approximately twothirds of the RPB5 gene was removed and replaced with the HIS3 gene to produce the allele rpb5 1 :: HIS3 (Fig. $8 \mathrm{~A})$. The entire protein-coding regions of $R P B 6$ and $R P B 8$ were replaced by $U R A 3$ (rpb6 $1:: U R A 3$ ) (Fig. 8B) and LYS2 (rpb8 $1::$ LYS2) (Fig. 8C), respectively. The diploid cells obtained by this approach have one chromosome with a wild-type RNA polymerase subunit gene and one chromosome with a deletion allele. Tetrad analysis of the sporulation products of these diploid cells revealed that the deletion of either RPB5, RPB6, or RPB8 produces nonviable haploid cells (Table 2). Therefore, all three of the common subunit genes are essential for cell viability.

\section{Discussion}

We have isolated and characterized the genes that encode the three subunits common to nuclear RNA polymerases in $S$. cerevisiae. We find that RPB5, RPB6, and $R P B 8$ are single-copy genes that reside on chromosomes II, XVI, and XV, respectively. Although the RPB5, RPB6, and RPB8 subunits of RNA polymerase II appear, by a variety of criteria, to be identical to their counterparts in RNA polymerases I and III (Buhler et al. 1976b, 1980; Valenzuela et al. 1976; Huet et al. 1982; Breant et al.

\section{A. RPB5}

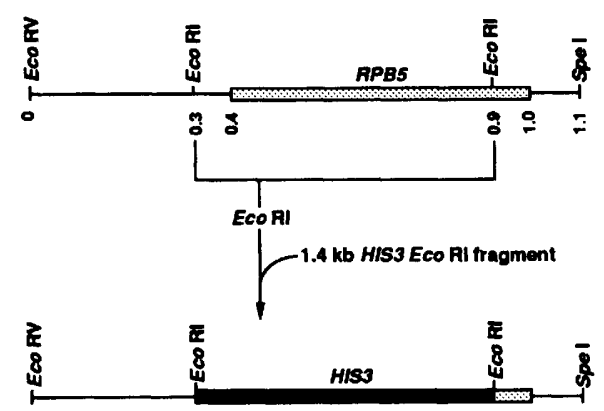

\section{B. RPB 6}

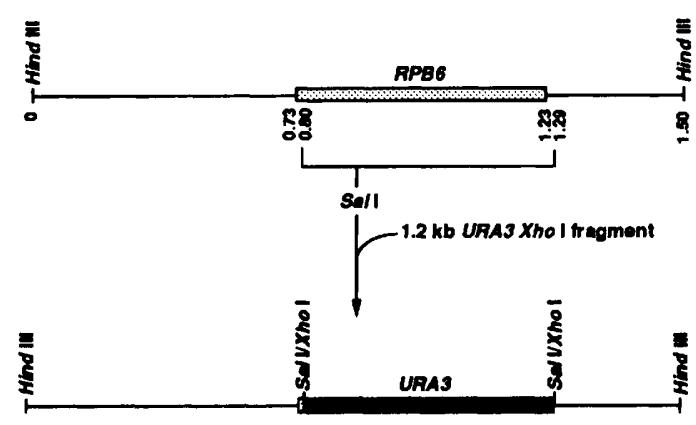

\section{C. $R P B 8$}

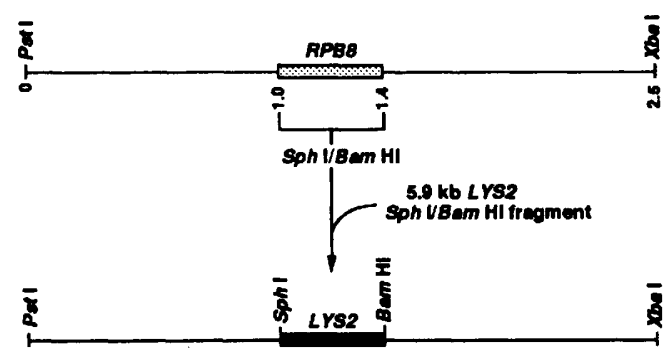

Figure 8. Construction of $R P B 5, R P B 6$, and $R P B 8$ gene disruptions. The boxed regions indicate coding sequence. The numbers below each starting DNA fragment represent approximate length (in $\mathrm{kb}$ ). The resulting gene replacements are not drawn to scale. The EcoRI restriction fragment containing $R P B 5$ DNA includes 65 bp of DNA $5^{\prime}$ to the RPB5-coding sequence; this 65 -bp region is within the $5^{\prime}$-untranslated leader of the RPB5 mRNA. 
Table 2. Tetrad analysis of diploid cells with RPB5, RPB6, or RPB8 gene replacements

\begin{tabular}{llllllr}
\hline \multirow{2}{*}{ Subunit } & Genotype at & \multicolumn{4}{c}{ Viable spores per tetrad a } \\
& target locus & 1 & 2 & 3 & 4 \\
\hline RPB5 & $R P B 5 / r p b 5 \Delta 1::$ HIS3 & 13 & 34 & 0 & 0 \\
RPB6 & $R P B 6 / r p b 6 \Delta 1::$ URA3 & 15 & 28 & 0 & 0 \\
RPB8 & $R P B 8 / r p b 8 \Delta 1::$ LYS2 & 12 & 22 & 0 & 0 \\
\hline
\end{tabular}

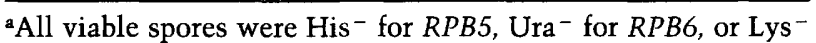
for $R P B 8$.

1983), it is not clear whether each of the common subunit proteins is encoded by a single gene or multiple related genes. The fact that $R P B 5, R P B 6$, and $R P B 8$ are single-copy genes indicates that each of the common subunits is truly identical in the three nuclear RNA polymerases. In addition, the observation that epitopetagged RPB6 protein coprecipitates with polypeptides described for RNA polymerases I, II, and III provides supporting evidence that the RPB6 gene product is assembled into all three nuclear RNA polymerases. Finally, the common subunit genes specify essential components of the eukaryotic RNA polymerases, as deletion of any one of these genes is lethal to haploid yeast cells.

The proteins encoded by $R P B 5, R P B 6$, and $R P B 8$ have predicted molecular masses of 25,038, 17,857, and 16,468 daltons, respectively. RPB5 is a very basic protein with a pI of 10.15, whereas both RPB6 and RPB8 are quite acidic, with pI values of 5.15 and 4.28, respectively. The predicted molecular mass of RPB6 is somewhat less than that its apparent molecular mass of 23 $\mathrm{kD}$, as estimated by SDS-PAGE (Sentenac 1985). RPB6 is phosphorylated (Buhler et al. 1976a; Bell et al. 1977), accounting for its reduced SDS-polyacrylamide gel mobility.

RNA polymerases I, II, and III share a variety of features and functions. They are large multisubunit enzymes composed of two very large subunits and 8-11 smaller proteins that include the three common subunits. Each of the RNA polymerases are assembled and transported into the nucleus. All three enzymes must recognize transcription factors that facilitate specific promoter recognition. The polymerases also bind template DNA and nucleoside triphosphate substrates and catalyze the template-dependent synthesis of RNA. Finally, these enzymes terminate RNA synthesis at or near specific sites, probably in concert with termination factors.

Which of the functions shared by the three nuclear RNA polymerases are carried out by the highly conserved two large subunits, and which are performed by the three common subunits? The two large subunits of prokaryotic RNA polymerases have the ability to interact with transcription factors, to bind DNA, to bind nucleoside triphosphate substrates, and to catalyze RNA synthesis (Yura and Ishihama 1979; Chamberlin 1982). The sequence similarity of the two large RNA polymerase subunits in eukaryotes and prokaryotes has led investigators to suggest that the two large subunits perform similar functions in eukaryotes and prokaryotes. Indeed, the two large eukaryotic RNA polymerase II subunits are capable of binding DNA and nucleoside triphosphates, and the second largest subunit is thought to contain the catalytic site (Cho and Kimball 1982; Carroll and Stollar 1983; Riva et al. 1987).

The sequences of the common subunits provide clues to their functions by helping to eliminate some possible functions. The common subunits lack known DNAbinding domains such as zinc fingers, leucine zippers, or helix-turn-helix motifs. They also lack nucleosidebinding motifs. Thus, these subunits are probably not directly involved in DNA or nucleoside triphosphate binding.

The common subunits are probably important for a function shared by the nuclear RNA polymerases such as transcriptional efficiency, nuclear localization, enzyme stability, or coordinate regulation of rRNA, mRNA, and tRNA synthesis. It is attractive to consider the possibility that the cell could coordinate a general increase or reduction in RNA synthesis via the common subunits. Modification of one or more of the common subunits might permit a rapid and general response to changes in cell cycle or growth conditions.

Seven yeast RNA polymerase II subunit genes have been isolated and characterized, including those for RNA polymerase common subunits. Table 3 summa-

Table 3. Yeast RNA polymerase II subunit genes

\begin{tabular}{|c|c|c|c|c|c|c|}
\hline Gene & $\begin{array}{l}\text { SDS-PAGE } \\
\text { mobility } \\
(\mathrm{kD})\end{array}$ & $\begin{array}{l}\text { Protein mass } \\
\text { (kD) }\end{array}$ & $\begin{array}{l}\text { Gene copy } \\
\text { number }\end{array}$ & $\begin{array}{l}\text { Chromosomal } \\
\text { location }\end{array}$ & $\begin{array}{l}\text { Deletion } \\
\text { viability }\end{array}$ & $\begin{array}{l}\text { Sequence } \\
\text { similarity }\end{array}$ \\
\hline$R P B 1$ & 220 & 190 & 1 & IV & inviable & $\beta^{\prime a}$ \\
\hline$R P B 2$ & 150 & 140 & 1 & $X V$ & inviable & $\beta^{b}$ \\
\hline$R P B 3$ & 45 & 35 & 1 & IX & inviable & $R P C 40^{\mathrm{c}}$ \\
\hline$R P B 4$ & 32 & 25 & 1 & $\mathrm{X}$ & conditional & \\
\hline RPB5 & 27 & 25 & 1 & II & inviable & 23-kD humand \\
\hline$R P B 6$ & 23 & 18 & 1 & XVI & inviable & \\
\hline$R P B 8$ & 14 & 16 & 1 & $X V$ & inviable & \\
\hline
\end{tabular}

aAllison et al. (1985).

bSweetser et al. (1987).

cMann et al. (1987).

dPati and Weismann (1989). 
rizes the principal features of these genes and the proteins that they encode. Each of the subunits is encoded by a single-copy gene. All of the RNA polymerase II subunit genes are essential for viability except $R P B 4$, whose deletion produces an enzyme that is thermally unstable. Although the two largest RNA polymerase II subunits have homologs in the prokaryotic RNA polymerase, the remaining eukaryotic subunits are not similar in sequence to the bacterial RNA polymerase subunits $\alpha$ or $\sigma$. Further investigation will be required to define precisely the functions of each of the eukaryotic RNA polymerase subunits, and the application of molecular genetic approaches using cloned subunit genes should facilitate these studies.

\section{Methods}

Yeast media

Strains were grown on YPD medium $[2 \%$ yeast extract, $1 \%$ Bacto-Peptone (Difco Laboratories, Detroit, Michigan), 2\% glucose]; YPD plates contained $2 \%$ agar. Dropout medium minus histidine, uridine, or lysine and low sulfate synthetic medium (LSM) has been described elsewhere (Julius et al. 1984; Nonet et al. 1987; Sherman et al. 1986). The ammonium sulfate concentration in LSM is $26 \mathrm{mg} /$ liter. No sulfate medium (NSM) is LSM without ammonium sulfate.

\section{Yeast strains}

Yeast strains are listed in Table 4. X2180 is the diploid derivate of S288C. Strain Z374, expressing an epitope-tagged RPB6 subunit, was constructed as follows. The plasmid pY2442 was introduced into Z320, a diploid heterozygous for the $r p b 6 \Delta 1$ deletion mutant, in which $R P B 6$ is replaced by $U R A 3$. Tetrads were dissected after sporulation of the $\mathrm{Z} 320$ derivatives and scored for complementation of the $r p b 6 \Delta 1$ lethal phenotype. Leu ${ }^{+}$ $\mathrm{Ura}^{+}$cells with wild-type growth phenotypes were recovered, indicating that the amino-terminal modification did not adversely affect RPB6. Strain Z374, which carries pY2442, was derived from this dissection. Plasmids and yeast strains used for epitope-tagging experiments involving RPB3 are described in Kolodziej and Young (1989).

\section{Protein sequence analysis}

Amino acid sequence was obtained for purified X2180-2 S. cerevisiae RNA polymerase II subunits using the method of Aebersold et al. (1987). Briefly, subunits were separated by SDSPAGE, the polypeptides were electroblotted onto nitrocellulose as described by Matsudaira (1987), and the proteins were stained with Ponceau $S$ to visualize individual subunit bands. Nitrocellulose containing the blotted subunit protein was destained and digested with trypsin, and tryptic peptides were purified by HPLC. Amino acid sequence was obtained from chromatography column fractions containing individual peptides from trypsin-digested 27- (RPB5), 23- (RPB6), or 14.5-kD (RPB8) polypeptides.

\section{Recombinant DNA libraries}

The $\lambda E M B L 3 a$ yeast genomic library was a gift of $M$. Snyder (Stanford University School of Medicine, Stanford, California) and was constructed with DNA from $S$. cerevisiae S288C. Plasmid sublibraries were constructed with DNA from $S$. cerevisiae N306, which is a S288C derivative. Plating and filter lifts of bacteriophage libraries were performed according to Davis et al. (1980). Transfer of bacterial colonies to filter membranes was done by placing a dry nitrocellulose circle over the colonies on the surface of a chilled plate $\left(4^{\circ} \mathrm{C}\right)$ for $1 \mathrm{~min}$. The filter was removed and left to air-dry for $10 \mathrm{~min}$. Lysis of the cells and denaturation of nucleic acids were achieved by placing the filters in the autoclave for $2 \mathrm{~min}$ on the dry cycle. After baking in a $80^{\circ} \mathrm{C}$ vacuum oven for $1-2 \mathrm{hr}$, the filters were washed for $30 \mathrm{~min}$ in $2 \times$ SSC (Duby et al. 1989) containing 0.1\% SDS. All libraries were probed with DNA oligonucleotides in sodium chloride/sodium citrate, as described by Duby et al. (1989).

\section{Plasmids}

RPB5 An 8-kb SalI DNA fragment was the smallest fragment contained in $A E M B L 3 a$ recombinant clones that hybridized to the RPB5 probes. The 8 -kb Sall fragment containing RPB5 DNA was ligated into the Sall site in pBluescript II KS + (Stratagene, San Diego, California), and the resulting plasmid was designated pRP51. The pRP56 plasmid contains the RPB5 gene in a 1.1-kb EcoRV-SpeI DNA fragment that has been ligated into the EcoRV-SpeI sites of pGem5.

RPB6 A pBluescript II $\mathrm{KS}^{+}$plasmid sublibrary was constructed with 1- to 2-kb HindIII yeast genomic DNA fragments. A clone isolated from this library, pRP61, was found to contain two HindIII DNA fragments of 1.5 and $1.3 \mathrm{~kb}$. The $1.5-\mathrm{kb}$ HindIII fragment containing the RPB6 gene was isolated and ligated into $\mathrm{pGem} 7$, and plasmids containing both orientations of the insert were recovered, called pRP66 and pRP67. Plasmid pRP61l containing the epitope-tagged $R P B 6$ gene was constructed by oligonucleotide-directed mutagenesis (Kunkel 1985 ) of pRP66 using the 61-mer oligonucleotide 5'-GGCTACAAGTGATCATGTACCCATACGACGTCCCAGACTACGCTTCAGACTACGAGGAGGC-3', which includes the 9-amino-acid influenza hemagglutinin epitope-coding sequences (underlined) flanked by $R P B 6$ sequences. The $1.5 \mathrm{~kb}$ HindIII fragment was excised from pRP611 as a SacI-XhoI fragment and inserted into the SacI-XhoI-cut yeast centromere plasmid pRP315 (Sikorski and Hieter 1989) containing the selectable marker $L E U 2$ to yield plasmid pY2442.

RPB8 The positive clones pSL104 and pSL105 were isolated from a pBluescript II $\mathrm{KS}^{+}$plasmid sublibrary. Both contained a 7.2-kb EcoRI insert. Plasmid pSL106 is pBluescript $\mathrm{II} \mathrm{KS}^{+}$with a 2.5-kb PstI-XbaI RPB8 DNA fragment derived from pSL104 inserted into the PstI and $\mathrm{XbaI}$ sites.

\section{DNA sequence and primer extension analysis}

All sequencing reactions with nondegenerate DNA primers were performed using denatured double-stranded plasmid DNA (Chen and Seeburg 1985), as suggested by the manual for the Sequenase Version 2.0 DNA Sequencing Kit (U.S. Biochemicals, Cleveland, Ohio). Sequencing reactions with the degenerate DNA oligonucleotides were carried out following the suggestions of Nichols and Dixon (1988), using the ${ }^{35}$ S Sequencing Pack (New England Biolabs, Beverly, Massachusetts). The plasmid constructs used for sequencing were pRP51, pRP61, and pSL104. Sequences were determined for both strands of DNA. Computer analysis of the sequences was carried out using the FASTA program (Pearson and Lipman 1988) to search the NBRF protein data base, IALIGN to align RPB5 and its human homolog, and PREDICT89 to determine amino acid content and isoelectric points (Robert Stroud, University of California at San Francisco). 
Table 4. Yeast strains

\begin{tabular}{|c|c|c|}
\hline Name & Genotype & Alias \\
\hline Z303 & 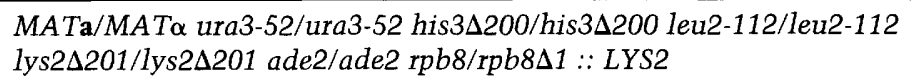 & YSL167 \\
\hline Z319 & 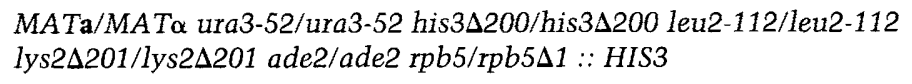 & WY-5 \\
\hline $\mathrm{Z} 320$ & 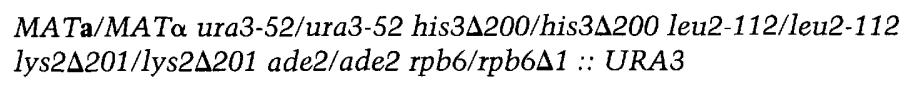 & WY-6 \\
\hline Z374 & 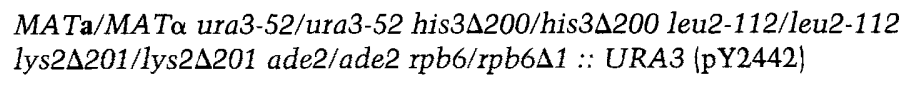 & - \\
\hline Z321 & 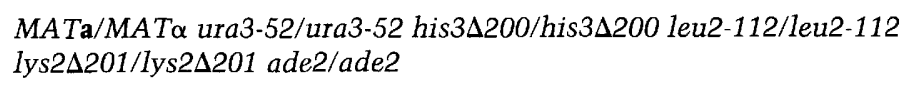 & $\mathrm{N} 222 \times \mathrm{N} 225$ \\
\hline N38 & MAT $\alpha$ rna2-1 ura3-1 ura3-2 ade1 ade2 tyr1 $G A L^{+}$ & RY15 \\
\hline N306 & $\begin{array}{l}\text { MATo ura3-52 his34200 ade2-101 leu2-77 lys2-801 trp1-901 } \\
\text { tyr1-501 gal4-542 gal80-538 }\end{array}$ & - \\
\hline $\mathrm{X} 2180-2$ & MATa/MATa mal-/mal- gal2/gal2 & Y4 \\
\hline
\end{tabular}

Source: This study.

Primer extension of the RPB5 transcripts involved annealing of an end-labeled DNA oligonucleotide to $S$. cerevisiae poly $(\mathrm{A})^{+}$RNA, followed by extension with reverse transcriptase (Williams and Mason 1985). Poly(A) ${ }^{+}$RNA was prepared from yeast cells according to Elder et al. (1983).

\section{Gene copy number: Southern analysis}

Hybridization and wash conditions were as described by Davis et al. (1980). Baked nitrocellulose filters containing blotted genomic DNA restriction fragments were prehybridized for $1 \mathrm{hr}$ at $37^{\circ} \mathrm{C}$ in a solution containing $5 \times$ SSPE plus $0.3 \%$ SDS $(20 \times$ SSPE consists of $3.6 \mathrm{M}$ sodium chloride, $0.2 \mathrm{M}$ sodium phosphate, $0.16 \mathrm{M}$ sodium hydroxide, and $20 \mathrm{mM}$ EDTA), $100 \mu \mathrm{g} / \mathrm{ml}$ denatured salmon sperm DNA, and 50\% formamide. Denatured radiolabeled probe was added to the hybridization mix, and the filter was hybridized at $42^{\circ} \mathrm{C}$ overnight. Filters were washed at $45^{\circ} \mathrm{C}$ in $2 \times$ SSPE plus $0.2 \%$ SDS for $1 \mathrm{hr}$.

For copy number analysis of $R P B 5$, the radiolabeled probe was made from a 650-bp EcoRI fragment that includes nucleotides 50-698 (Fig. 1). The probe used for RPB6 consisted of a 500-bp XmnI-HindIII fragment containing DNA from nucleotide 385 to the HindIII site 200 bp $3^{\prime}$ of the RPB6-coding region (Fig. 3). A 700-bp SpeI fragment was used to probe RPB8 DNA. This probe included the entire $R P B 8$-coding sequence plus 209 bp $5^{\prime}$ and $48 \mathrm{bp} 3^{\prime}$ of the coding sequence.

\section{Cell labeling}

Cells $\left(5 \times 10^{7}\right)$ grown in LSM were harvested by centrifugation at $2000 \mathrm{rpm}$ for $5 \mathrm{~min}$, resuspended in $1 \mathrm{mCi}$ of $\left.{ }^{35} \mathrm{~S}\right]$ methionine (New England Nuclear, $686 \mathrm{Ci} / \mathrm{mmole}$ ) and $12 \mu \mathrm{l}$ of $5 \times \mathrm{NSM}$, and incubated for $5 \mathrm{~min}$ at the appropriate temperature. One milliliter of LSM was added, and the culture was transferred to a disposable 125-ml Erlenmeyer flask. After incubation with shaking for $20 \mathrm{~min}, 10 \mathrm{ml}$ of LSM was added, and growth continued for $95 \mathrm{~min}$.

\section{Immunoprecipitation of RNA polymerases}

Immunoprecipitation with the 12CA5 antibody was performed as described (Kolodziej and Young 1989), except that immuno- precipitates were washed twice with buffer B [20 mM HEPES$\mathrm{NaOH}(\mathrm{pH} 7.9), 5 \%$ glycerol, $10 \mathrm{~mm}$ EDTA] containing $0.4 \mathrm{M}$ ammonium sulfate and once with buffer B containing $0.05 \mathrm{M}$ ammonium sulfate, prior to resuspension in loading buffer (Laemmli 1970). Immunoprecipitates were examined by SDSPAGE and fluorography as described (Kolodziej and Young 1989 .

\section{Construction of RPB5, RPB6, and RPB8 deletions}

The $\operatorname{rpb} 5 \Delta 1:: H I S 3$ allele was constructed by removing a 650 bp EcoRI fragment (which encodes approximately two-thirds of the RPB5 protein) from pRP56 and inserting a 1.8-kb HIS3 fragment. This plasmid is called pRP57. DNA containing the rpb5 $1::$ HIS3 allele was removed from pRP57 by digestion with EcoRV and SpeI, and the yeast diploid Z321 was transformed with this DNA. Genomic DNA was prepared (Sherman et al. 1986) from the $\mathrm{His}^{+}$transformant $\mathrm{Z} 319$ and subjected to Southern analysis to verify the substitution of the chromosomal copy of RPB5 with RPB5D1::HIS3. Z319 cells were sporulated, and tetrad analysis was performed (Sherman et al. 1986).

$r p b 6 \Delta 1:: U R A 3$ was constructed by replacement of the entire RPB6-coding region of pRP66 with a Sall restriction site using oligonucleotide-directed mutagenesis (Kunkel 1985). $U R A 3$ was inserted into the Sall site as a XhoI DNA fragment created by addition of XhoI linkers to a $1.14-\mathrm{kb}$ HindIII URA3 fragment. The resulting plasmid, pRP68, was cut with HindIII, and the URA3-containing fragment was used to transform $\mathrm{Z} 321$. The $\mathrm{Ura}^{+}$transformant $\mathrm{Z} 320$ was checked for appropriate replacement of $R P B 6$ with $r p b 6 \Delta 1:: U R A 3$, sporulated, and subjected to tetrad analysis.

$r p b 8 \Delta 1::$ LYS 2 was constructed by replacing the entire RPB8-coding region of pSL106 with adjacent SphI and BamHI sites using oligonucleotide-directed mutagenesis to produce pSL111. LYS2 was inserted into the SphI-BamHI site of pSL111 as a $5.9-\mathrm{kb} S p h \mathrm{I}-\mathrm{BamHI}$ fragment. The resulting plasmid, pSL119, was cleaved with $P_{s t I}$ and $X b a I$, and the DNA fragments were used to transform Z321. The $\mathrm{Lys}^{+}$transformant Z303 was checked for appropriate replacement of $R P B 8$ with $r p b 8 \Delta 1:: L Y S 2$, sporulated, and subjected to tetrad analysis. 


\section{Acknowledgments}

We thank William Lane of the Harvard Microchemistry Facility for HPLC and protein sequence analysis of RPB5, RPB6, and RPB8 peptides and Mike Nonet for $S$. cerevisiae poly(A)+ RNA. This work was supported by U.S. Public Health Service Grant GM-34365, by U.S. Public Health Service postdoctoral fellowship GM-11605 to N.A.W. from the National Institutes of Health, and by fellowship DRG969 to S.-M.L. from the Damon Runyon-Walter Winchell Cancer Fund. P.A.K. is a National Institutes of Health predoctoral trainee and R.A.Y. is a Burroughs Wellcome Scholar.

\section{References}

Aebersold, R.H., J. Leavitt, R.A. Saavedra, and L.E. Hood. 1987. Internal amino acid sequence analysis of proteins separated by one- or two-dimensional gel electrophoresis after in situ protease digestion on nitrocellulose. Proc. Natl. Acad. Sci. 84: 6970-6974.

Ahearn, J.M., Jr., M.S. Bartolomei, M.L. West, L.J. Cisek, and J.L. Corden. 1987. Cloning and sequence analysis of the mouse genomic locus encoding the largest subunit of RNA polymerase II. $J$. Biol. Chem. 262: 10695-10705.

Allison, L.A., M. Moyle, M. Shales, and C.J. Ingles. 1985. Extensive homology among the largest subunits of eukaryotic and prokaryotic RNA polymerases. Cell 42: 599-610.

Bell, G.I., P. Valenzuela, and W.J. Rutter. 1977. Phosphorylation of yeast DNA-dependent RNA polymerases in vivo and in vitro. J. Biol. Chem. 252: 3082-3091.

Biggs, J., L.L. Searles, and A. L. Greenleaf. 1985. Structure of the eukaryotic transcription apparatus: Features of the gene for the largest subunit of Drosophila RNA polymerase II. Cell 42: 611-621.

Breant, B., J. Huet, A. Sentenac, and P. Fromageot. 1983. Analysis of yeast RNA polymerases with subunit-specific antibodies. J. Biol. Chem. 258: 11968-11973.

Buhler, J.-M., F. Iborra, A. Sentenac, and P. Fromageot. 1976a. The presence of phosphorylated subunits in yeast RNA polymerases A and B. FEBS Lett. 71: 37-41.

- 1976b. Structural studies on yeast RNA polymerases. Existence of common subunits in RNA polymerases $A(I)$ and B (II). J. Biol. Chem. 251: 1712-1717.

Buhler, J.-M., J. Huet, K.E. Davies, A. Sentenac, and P. Fromageot. 1980. Immunological studies of yeast nuclear RNA polymerase at the subunit level. $/$. Biol. Chem. 255: 99499954.

Carroll, S.B. and B.D. Stollar. 1983. Conservation of a DNAbinding site in the largest subunit of eukaryotic RNA polymerase II. J. Mol. Biol. 170: 777-790.

Chamberlin, M.J. 1982. Bacterial DNA-dependent RNA polymerases. In The enzymes (ed. P. Boyer), pp. 61-86. Academic Press, New York.

Chen, E.Y. and P.H. Seeburg. 1985. Supercoil sequencing: A fast and simple method for sequencing plasmid DNA. DNA 4: $165-170$.

Cho, J.M. and A.P. Kimball. 1982. Probes of eukaryotic DNAdependent RNA polymerase II-I. Binding of $9-\beta$-D-arabinofuranosyl-6-mercaptopurine to the elongation subsite. Biochem. Pharmacol. 31: 2575-2581.

Cho, K.W.Y., K. Khalili, R. Zandomeni, and R. Weinmann. 1985. The gene encoding the large subunit of human RNA polymerase II. J. Biol. Chem. 260: 15204-15210.

Corden, J.L., D.L. Cadena, J.M. Ahearn, and M.E. Dahmus. 1985. A unique structure at the carboxyl terminus of the largest subunit of eukaryotic RNA polymerase II. Proc. Natl. Acad. Sci. 82: 7934-7938.

Davis, R.W., D. Botstein, and J.R. Roth. 1980. Advanced bacterial genetics: A manual for genetic engineering. Cold Spring Harbor Laboratory, Cold Spring Harbor, New York.

Dayoff, M.O., W.C. Barker, and L.T. Hunt. 1983. Establishing homologies in protein sequences. Methods Enzymol. 91: 524-545.

Duby, A., K.A. Jacobs, and A. Celeste. 1989. Screening of recombinant DNA libraries. Using synthetic oligonucleotides as probes. In Current protocols in molecular biology leds. F.M. Ausubel, R. Brent, R.E. Kingston, D.D. Moore, J.G. Seidman, J.A. Smith, and K. Struhl), pp. 6.4.1-6.4.10. Greene/John Wiley, New York.

Elder, R.T., E.Y. Loh, and R.W. Davis. 1983. RNA from the yeast transposable element Ty1 has both ends in direct repeats, a structure similar to retrovirus RNA. Proc. Natl. Acad. Sci. 80: 2432-2436.

Falkenburg, D., B. Dworniczak, D. Faust, and E.K.F. Bautz. 1987. RNA polymerase II in Drosophila. Relation of its $140,000 M_{x}$ subunit to the $\beta$ subunit of Escherichia coli RNA polymerase. J. Mol. Biol. 195: 929-937.

Faust, D.M., R. Renkawitz-Pohl, D. Falkenburg, A. Gasch, S. Bailojan, R.A. Young, and E.K.F. Bautz. 1986. Cloning and identification of the gene coding for the 140-kd subunit of Drosophila RNA polymerase II. EMBO I. 5: 741-746.

Field, J., J.-I, Nikawa, D. Broek, B. MacDonald, L. Rodgers, I.A. Wilson, R.A. Lerner, and M. Wigler. 1988. Purification of a $R A S$-responsive adenylyl cyclase complex from Saccharomyces cerevisiae by use of an epitope addition method. Mol. Cell. Biol. 8: 2159-2165.

Greenleaf, A.L. 1983. Amanitin-resistant RNA polymerase II mutations are in the enzymes's largest subunit. $/$. Biol. Chem. 258: 13403-13406.

Huet, J., L. Phalente, G. Buttin, A. Sentenac, and P. Fromageot. 1982. Probing yeast RNA polymerase A subunits with monospecific antibodies. EMBO J. 1: 1193-1198.

Ingles, J.C., H.J. Himmelfarb, M. Shales, A.L. Greenleaf, and J.D. Friesen. 1984. Identification, molecular cloning, and mutagenesis of Saccharomyces cerevisiae RNA polymerase genes. Proc. Natl. Acad. Sci. 81: 2157-2161.

Julius, D., R. Schekman, and J. Thorner. 1984. Glycosylation and processing of prepro- $\alpha$-factor through the yeast secretory pathway. Cell 36: 309-318.

Kolodziej, P.A. and R.A. Young. 1989. RNA polymerase II subunit RPB3 is an essential component of the mRNA transcription apparatus. Mol. Cell Biol. 9: 5387-5394.

Kunkel, T.A. 1985. Rapid and efficient site-specific mutagenesis without phenotypic selection. Proc. Natl. Acad. Sci. 82: $488-492$.

Laemmli, U.K. 1970. Cleavage of structural proteins during assembly of the head of bacteriophage T4. Nature 227: 680685.

Lewis, M.K. and R.R. Burgess. 1982. Eukaryotic RNA polymerases. In The enzymes (ed. P. Boyer), pp. 109-153. Academic Press, New York.

Mann, C., J.-M. Buhler, I. Treich, and A. Sentenac. 1987. $R P B 40$, a unique gene for a subunit shared between yeast RNA polymerase A and C. Cell 48: 627-637.

Matsudaira, P. 1987. Sequence from picomole quantities of proteins electroblotted onto polyvinylidene difluoride membranes. J. Biol. Chem. 262: 10035-10038.

Memet, S., W. Saurin, and A. Sentenac. 1988a. RNA polymerases B and C are more closely related to each other than to RNA polymerase A. I. Biol. Chem. 263: 10048-10051.

Memet, S., M. Gouy, C. Marck, A. Sentenac, and J.-M. Buhler. 
1988b. RPA190, the gene coding the largest subunit of yeast RNA polymerase A. J. Biol. Chem. 263: 2830-2839.

Nichols, R. and J.E. Dixon. 1988. Rapid identification of clones using the same degenerate oligonucleotide mixture for both screening and sequencing. Anal. Biochem. 170: 110-115.

Nonet, M., D. Sweetser, and R.A. Young. 1987. Functional redundancy and structural polymorphism in the large subunit of RNA polymerase II. Cell 50: 909-915.

Pati, U.K. and S.M. Weissman. 1989. Isolation and molecular cloning of a cDNA encoding the $23 \mathrm{kDa}$ subunit of human RNA polymerase II. J. Biol. Chem. 264: 13114-13121.

Pearson, W.R. and D.J. Lipman. 1988. Improved tools for biological sequence comparison. Proc. Natl. Acad. Sci. 85: 24442448.

Riva, M., S. Memet, J.-Y. Micouin, J. Huet, I. Treich, J. Dassa, R. Young, J.-M. Buhler, A. Sentenac, and P. Fromageot. 1986. Isolation of structural genes for yeast RNA polymerases by immunological screening. Proc. Natl. Acad. Sci. 83: 15541558.

Riva, M., A.R. Schaffner, A. Sentenac, G.R. Hartmann, A.A. Mustaev, E.F. Zaychikov, and M.A. Grachev. 1987. Active site labeling of the RNA polymerases $A, B$ and $C$ from yeast. I. Biol. Chem. 262: 14377-14380.

Rothstein, R.J. 1983. One-step gene disruption in yeast. Methods Enzymol. 101: 202-211.

Searles, L.L., R.S. Jokerst, P.M. Bingham, R.A. Voelker, and A.L. Greenleaf. 1982. Molecular cloning of sequences from a Drosophila RNA polymerase II locus by P element transposon tagging. Cell 31: 585-592.

Sentenac, A. 1985. Eukaryotic RNA polymerases. Crit. Rev. Biochem. 18: 31-91.

Sherman, F., G.R. Fink, and J.B. Hicks. 1986. Laboratory course manual for methods in yeast genetics. Cold Spring Harbor Laboratory, Cold Spring Harbor, New York.

Sikorski, R.S. and P. Hieter. 1989. A system of shuttle vectors and yeast host strains designed for efficient manipulation of DNA in Saccharomyces cerevisiae. Genetics 122: 19-27.

Sweetser, D., M. Nonet, and R.A. Young. 1987. Prokaryotic and eukaryotic RNA polymerases have homologous core subunits. Proc. Nat1. Acad. Sci. 84: 1192-1196.

Valenzuela, P., G.I. Bell, F. Weinburg, and W.J. Rutter. 1976. Yeast DNA-dependent RNA polymerases I, II, and III. The existence of subunits common to the three enzymes. Biochem. Biophys. Res. Commun. 71: 1319-1325.

- 1978. Isolation and assay of eukaryotic DNA dependent RNA polymerases. Methods Cell Biol. 19: 1-26.

Williams, P.G., and J.G. Mason. 1985. Hybridization in the analysis of recombinant DNA. In Nucleic acid hybridization: A practical approach (ed. B.D. Hames and S.J. Higgens), pp. 139-160. IRL Press, Washington, D.C.

Woychik, N.A. and R.A. Young. 1989. RNA polymerase II subunit RPB4 is essential for high- and low-temperature yeast cell growth. Mol. Cell. Biol. 9: 2854-2859.

Young, R.A. and R.W. Davis. 1983. Yeast RNA polymerase II genes: Isolation with antibody probes. Science 222: 778782.

Yura, T. and A. Ishihama. 1979. Genetics of bacterial RNA polymerases. Annu. Rev. Genet. 13: 59-97. 


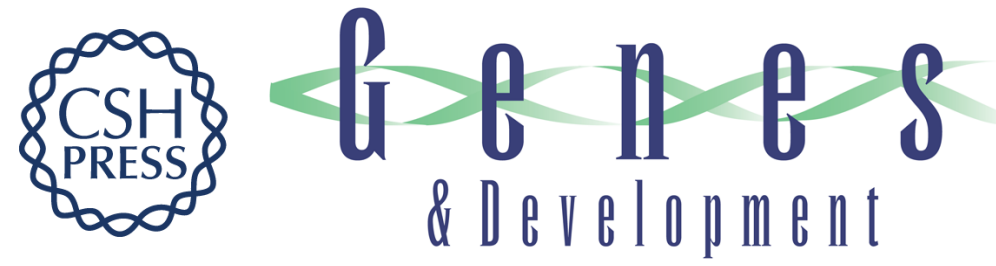

\section{Subunits shared by eukaryotic nuclear RNA polymerases.}

N A Woychik, S M Liao, P A Kolodziej, et al.

Genes Dev. 1990, 4:

Access the most recent version at doi:10.1101/gad.4.3.313

References This article cites 46 articles, 24 of which can be accessed free at: http://genesdev.cshlp.org/content/4/3/313.full.html\#ref-list-1

License

Email Alerting

Receive free email alerts when new articles cite this article - sign up in the box at the top Service right corner of the article or click here.

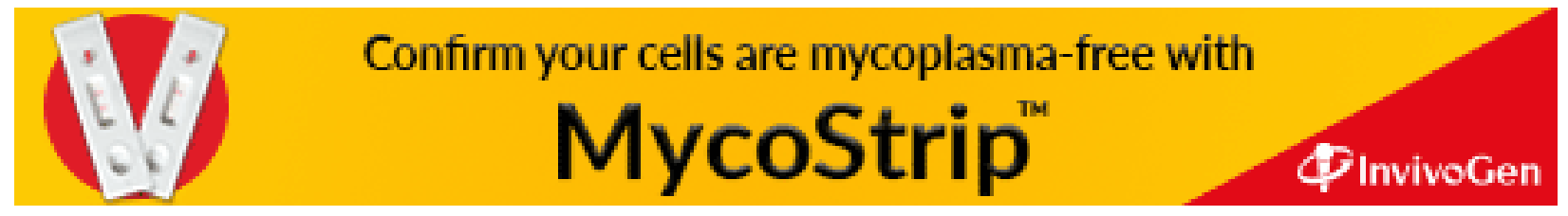

